\title{
CONHECIMENTO E VALOR: \\ A ÉTICA EM PRIMEIRA PESSOA DE WITTGENSTEIN E SUAS IMPLICAÇÕES PARA OS ESTUDOS DA TRADUÇÃO ${ }^{1}$
}

\section{Paulo Oliveira}

Que não seja imortal, posto que é chama

Mas que seja infinito enquanto dure.

(Vinícius de Moraes)

\section{Escopo e lugar da ética}

Que escopo devemos dar ao conceito de ética nos Estudos da Tradução, para que ele dê conta das necessidades específicas da área? Uma possibilidade é lançar mão da acepção corrente do termo, no sentido de um catálogo de normas de conduta para o exercício profissional. Nesse caso, a ética assemelha-se a um "contrato de adesão": posso até não concordar plenamente com os termos do contrato, mas submeto-me a eles para exercer a profissão — da mesma forma que aceito os termos de um regulamento de condomínio para ter acesso à moradia. Em outras palavras: a adesão ao contrato implica a aceitação das eventuais penalidades nele previstas, em termos legais, mas não me obriga a internalizar esses preceitos. Pelo contrário: posso até fazer-lhes sérias restrições, aceitando-os por uma mera questão de conveniência, e quem sabe até tentar modificá-los, se me for dada a oportunidade.

Muito do que se fala e escreve sobre a ética na tradução movimenta-se no escopo dessa dimensão mais pragmática, técnico-legal, do termo. A questão dos direitos autorais, por exemplo, das obrigações do tradutor e da editora (ou do cliente), passa certamente por aí. Casos concretos de como e onde isso ocorre foram fornecidos por Maria Clara Castellões de Oliveira (código de ética do SINTRA) e Lenita Esteves (código de ética dos intérpretes judiciais) em suas respectivas apresentações em Ouro Preto, e poderão ser encontrados na presente compilação. Tais aspectos são, de fato, relevantes, e têm grande impacto na inserção social do tradutor e no estatuto da atividade tradutória no mercado de trabalho. No entanto,

\footnotetext{
${ }^{1}$ O presente trabalho recebeu apoio da FAPESP (Processo $n^{\circ}$ 2009/09364-0) e situa-se na interface de dois Grupos de Trabalho do CNPq. Agradeço aos membros do primeiro, Filosofia da Linguagem e do Conhecimento, por sua discussão cuidadosa e pelas sugestões feitas antes e depois da apresentação feita no X Encontro Nacional de Tradutores e IV Encontro Internacional de Tradutores ocorridos em setembro de 2009 em Ouro Preto. Aos membros do segundo, MultiTrad - Abordagens Multidisciplinares da Tradução, agradeço pela calorosa acolhida e a possibilidade desta publicação. Por restrições de espaço, e levando também em conta o público-alvo de não filósofos, limito-me aqui a assinalar alguns pontos basilares, nem sempre desenvolvendo de modo sistemático uma discussão mais técnica da obra de Wittgenstein, e evitando meandros terminológicos relevantes sobretudo para especialistas - embora alguns deles tenham de ser, necessariamente, tematizados.
} 
num certo sentido, sua importância é mais política/jurídica (e econômica) do que propriamente ética, na medida em que a ética, numa dimensão mais profunda, envolve também o comprometimento individual, a adesão — quiçá incondicionada — a um conjunto de valores.

Uma variante semelhante à puramente pragmática é aquela em que a definição de uma determinada postura ética é mobilizada como argumento na defesa dessa ou daquela opção estética em projetos tradutórios, tais como os de Antoine Berman, dos irmãos Campos ou de Lawrence Venuti, como discutido por Cristina Rodrigues (2007). Aqui, há certamente uma adesão dos autores a esse conjunto de valores (que eles mesmos definiram), os quais podem então ser apresentados como $a$ solução ética para o contexto em que atuam. O interessante é que essa opção ético/estética tem implicações políticas na disputa de espaço com opções concorrentes. O que está em jogo é também uma disputa de poder, o reconhecimento como estratégia adequada, ou quiçá melhor do que as outras, no trato das questões ético/estéticas envolvidas. Não é a adesão a um "contrato" de natureza pragmática; mas implica a proposta de que outros (tradutores) devam aderir a determinado projeto, a determinada concepção tradutória - como estratégia de assimilação ou resistência, ou apropriação do outro (o autor traduzido), para ficarmos com os exemplos já aludidos.

No primeiro caso, a instância decisória pode ser externa, se não houver internalização do "contrato". No segundo, a adesão pressupõe a internalização dos valores, que passam então a ser utilizados no julgamento do fazer de outros, ou seja, meu critério passa a ser o critério geral. Aqui entra em jogo, portanto, a definição da instância decisória (internalizada ou não) e sua generalidade, levando no limite à possibilidade de sua universalização.

A ética é algo absoluto e universal, ou pode ser relativa e individual? Tais qualificadores aplicam-se também aos fundamentos do conhecimento, numa variante da mesma pergunta - e a forma como os aplicarmos dirá muito sobre a concepção de linguagem que mobilizamos nos Estudos da Tradução. Creio que boa parte da polêmica entre as chamadas posturas essencialistas (ou tradicionais) e as variantes pós-estruturalistas na área têm por base uma compreensão inadequada das possibilidades combinatórias desse conjunto de conceitos (e outros mais).

$\mathrm{Na}$ história da Filosofia, um importante deslocamento foi feito por Kant, quando retirou da Igreja o estatuto de árbitro único e definitivo sobre o bem e o mal, ao inaugurar a autonomia do sujeito. Adicionalmente, seu imperativo categórico, segundo o qual devo pensar minhas ações de modo tal que elas possam tornar-se preceitos universais (cf. Kant, 1980: 129), permite ao mesmo tempo universalizar a responsabilidade do indivíduo e resguardar sua 
autonomia face a uma instância decisória externa. ${ }^{2}$ Sendo a responsabilidade última (e absoluta) do indivíduo, ele não mais pode delegar a justificação de suas decisões a um código com interpretações eventualmente externas, sobre as quais não tenha poder de influência.

O imperativo categórico kantiano é, portanto, absoluto e universal. ${ }^{3} \mathrm{Na}$ discussão contemporânea, por sua vez, persiste uma tendência a alinhar automaticamente esses dois conceitos e, de modo análogo, o binômio regional e relativo. Tal divisão é utilizada tanto nas discussões sobre os fundamentos do sentido quanto dos valores. O mesmo não se aplica à filosofia de Wittgenstein, em cujo desenvolvimento as relações entre os fundamentos do sentido e os valores passaram por deslocamentos extremamente significativos, com implicações profundas para nosso entendimento do conceito de tradução, e de suas implicações ético/estéticas.

\section{2. Ética e tradução no "primeiro" Wittgenstein}

Para entendermos como as dimensões citadas acima se relacionam na obra do filósofo austríaco, um bom ponto de partida é aquilo que Brian McGuinness, em sua introdução à Ethics of will, chamou de "ética em primeira pessoa" de Wittgenstein. Segundo o autor, “Wittgenstein simplesmente não acreditava ser possível 'professar' uma teoria, com códigos morais, cujos fundamentos fossem racionais e justificáveis" (cf. Soulez, 2008: 1). Tal postura já está articulada no Tractatus (Wittgenstein, 1989a), onde, após afirmar que todas as proposições da lógica têm igual valor (6.4), o filósofo conclui que o sentido do mundo tem de estar fora dele, posto que o "ser-assim" do mundo é acidental, não podendo, portanto, ter nenhum valor intrínseco - pois se o tivesse não seria acidental (cf. 6.41). Conclui então que, por esse motivo, "não pode haver proposições da ética" (6.42). Por outro lado: "A ética é transcendental (ética e estética são uma coisa só)" (6.421).

Dizer que a ética/estética tem caráter transcendental significa que ela(s) organiza(m) o mundo, tal como o percebemos, mas o faz(em) de fora, ao passo que a lógica organiza o mundo de dentro. Não cabe aqui discutir o rol de questões técnicas implicadas nessas

\footnotetext{
${ }^{2}$ Para uma discussão introdutória que contempla bem esses aspectos, vide os dois textos de Maurício Keinert (s.d.) na revista Mente e Cérebro \& Filosofia, n.3. A discussão inaugural do tema, contemplando a tensão entre o absoluto e o particular, está na Fundamentação da metafísica dos costumes (Kant, 2008).

${ }^{3} \mathrm{O}$ caráter absoluto do imperativo categórico kantiano não é desprovido de problemas. Até que ponto, por exemplo, o preceito kantiano "nunca minta" traduz-se necessariamente numa ação ética? Em outros termos: não haveria situações em que mentir seria mais ético do que falar a verdade? Tortura, regimes de exceção etc. são casos em que a aplicação incondicional do preceito seria questionável. Para uma apresentação ficcionalizada desse problema, vide Babensberger (2004).
} 
asserções, mas vale a pena nos determos sobre a dimensão do absoluto que elas trazem em seu bojo.

Na Conferência sobre a ética, elaborada em 1929/30, Wittgenstein (1965) fornece um exemplo extremamente ilustrativo da distinção entre os valores aplicados de forma relativa ou absoluta. Segundo o filósofo, se alguém disser "Sei que estou jogando mal tênis, mas não quero jogar de modo melhor", não teremos dificuldade em aceitar essa postura. Diferente seria nossa reação diante da afirmação: "Sei que estou me comportando mal, mas não quero comportar-me de modo melhor". Aqui, uma reação baseada em preceitos éticos levaria necessariamente a uma resposta como: "Bem, você deveria querer comportar-se de modo melhor".

Em suas observações sobre a concepção wittgensteiniana de ética, Rush Rhees (s.d.: 14) sugere que, face a um imperativo como esse ("você deveria"), uma reação natural seria perguntar: "E se eu não fizer isso" - quais seriam as consequências? Ora, formular uma tal pergunta significa entender que o tema comporta valores relativos. Isso cabe perfeitamente quando estamos diante de um "contrato de adesão" cujos termos não tenham sido internalizados, ou que seja percebido sobretudo como mero quadro jurídico-formal. Esse poderia ser o caso dos direitos autorais, das obrigações entre as partes, das normas de um condomínio etc. Mas certamente não é esse o caso quando o valor tem caráter absoluto, no sentido propriamente ético como o entende Wittgenstein.

Por outro lado, esse absoluto não implica universal, posto que não haveria como definir um sistema ético como melhor do que os outros. Os sistemas éticos simplesmente funcionam de modos diferentes uns dos outros - e tais diferenças não são comparáveis àquelas entre as diversas teorias científicas:

Ou bem imaginemos que alguém nos diz: "Um dos sistemas de ética deve ser o correto, ou o que chegue mais próximo de sê-lo". Bem, suponhamos que eu afirme que a ética cristã é a correta. Nesse caso, estou formulando um juízo de valor. $\mathrm{O}$ que equivale a adotar a ética cristã. Não é o mesmo que dizer que entre várias teorias físicas deverá haver uma que seja a correta. A maneira pela qual uma realidade corresponde — ou entra em conflito — com uma teoria física não tem contrapartida aqui.

Afirmar que existem diversos sistemas de ética não equivale a afirmar que todos eles sejam igualmente corretos. Isso carece de sentido. Da mesma maneira que careceria de sentido afirmar que cada um deles é correto a partir de seu próprio ponto de vista. Isso apenas significaria que cada um joga como joga. (Wittgenstein, comunicação oral, 1945; apud Rhees, s.d.: 18) 
Um sistema de ética não pode ser "correto" ou "falso" porque "correção vs. falsidade" pressupõe um quadro de referência com base no qual tal decisão possa ser tomada. ${ }^{4}$ Ora, o sistema de ética é, ele mesmo, o quadro de referência a partir do qual posso julgar as ações (reais ou virtuais) como boas ou más, adequadas ou não, etc. Por esse motivo, ele tem uma dimensão de absoluto, algo que não se deixa reduzir a um cálculo de perdas e ganhos, como na adesão a um "contrato" ou na relação com uma instância julgadora externa. Esse absoluto, por sua vez, implica necessariamente a internalização dos valores que compõem o sistema daí a ideia da supracitada "ética em primeira pessoa" à qual se refere McGuinness quando fala de Wittgenstein.

De resto, a ética estaria necessariamente ligada à resolução de um problema. Rhees cita uma conversa de 1942, na qual Wittgenstein teria apontado para o fato de ser raro "encontrar livros de ética nos quais não se mencionasse algum genuíno problema ético ou moral", e sugere que Wittgenstein aceitaria falar de problema "apenas se fosse possível imaginar ou reconhecer uma solução" (p. 16). Abstenho-me aqui de tentar reproduzir os exemplos apresentados (como o assassinato de César e a opção de um cientista pela família ou pela pesquisa), pois o espaço disponível não nos permite fazê-lo de forma adequada. Registro apenas que eles ilustram bem os princípios gerais elencados acima: 1) a existência de um problema ético; 2) a inexistência de uma solução automática; 3) a possibilidade ou vislumbre de se encontrar uma solução. Em outras palavras: onde não houver a possibilidade de uma solução (dentro de determinado quadro de referência), não haverá um problema ético - mas sim uma pseudoquestão, poderíamos concluir. E onde o próprio quadro de referência já fornecer soluções prontas, à guisa de receita padrão, tampouco haverá um problema ético o que nos afasta, uma vez mais, da ética "relativa" associada ao cumprimento pura e simples de um catálogo de preceitos e procedimentos técnicos.

Mas qual seria a relação da ética com a tradução? Essa é uma questão em que houve deslocamentos sensíveis no desenvolvimento da obra do filósofo. Lembremos que, no chamado primeiro Wittgenstein (aquele do Tractatus), a ética/estética é algo que está fora do mundo, porque fora do espaço lógico (cf. 6.42). Já a tradução, por sua vez, embora nunca tenha recebido uma abordagem explícita enquanto conceito propriamente dito, i.e. embora

\footnotetext{
${ }^{4}$ É verdade que o acesso à realidade, aos fenômenos no/do mundo, também se dá através de um quadro de referência fornecido pelas diferentes teorias, por sua gramática interna. Esse tema foi explorado, dentre outros, por Thomas Kuhn (1987), cuja noção de paradigma é, de certa forma, tributária de Wittgenstein — ainda que não haja um reconhecimento direto disso, como na alusão a Ludwig Fleck feita no prefácio do livro de Kuhn. Wittgenstein, por sua vez, sempre distinguiu claramente a atividade filosófica da científica. Mas, para nossa discussão, por ora, basta lembrar que a ética/estética está fora do mundo; motivo pelo qual o mundo não pode ser usado como critério de verificação nesse âmbito.
} 
não tenha sido tematizada enquanto tal, certamente pode ser compreendida como uma expressão direta da forma lógica, daquilo que organiza o espaço interno ao qual os estados de coisas no mundo devem corresponder.

Ou seja: se a ética é externa e a tradução é interna ao espaço lógico, ética e tradução simplesmente não se tocam no Tractatus. Detenhamo-nos um pouco sobre este aspecto, que é pouquíssimo explorado — se não completamente ignorado - pelos comentadores de Wittgenstein.

O ponto em que mais próximo chegamos de uma definição de tradução no Tractatus encontra-se nos aforismos 4.014, 4.0141 e 4.015 (cf. Oliveira, 2007: 188-197). Trata-se de uma célebre análise da relação entre o disco gramofônico, a ideia musical e a partitura. Do trecho em questão, depreendemos que a tradução é aqui entendida como uma lei de projeção, uma regra geral que permite transitar entre diferentes linguagens, aparentemente díspares, mas que comungam uma mesma estruturação interna, a qual não reflete outra coisa senão a forma lógica da proposição.

$\begin{array}{cccc}A & B & \mathrm{~B} & \mathrm{C} \\ \text { partitura } & \leftarrow \mathrm{FL} \rightarrow & \text { sinfonia }\end{array}$

É possível traduzir entre partitura, sinfonia e disco porque os três fatos possuem a mesma estruturação interna. Nesse sentido, é a forma lógica comum que permite a passagem de uma coisa à outra. De modo semelhante, é a forma lógica comum a diferentes linguagens (línguas naturais ou notações simbólicas) o que permite a tradução, ou passagem de uma à outra. Poder-se-ia então dizer que, se a relação de afiguração entre a linguagem e o mundo é uma projeção vertical, a tradução entre diferentes línguas ou linguagens é uma projeção horizontal. Nesse sentido, as relações tradutórias seriam estritamente lógicas, não havendo espaço para uma avaliação ética da tradução — posto que a ética/estética fica fora do espaço lógico, como já assinalado acima. Essa compreensão coloca sérios problemas, sobretudo quando o que está em jogo é a tradução de objetos estéticos (literatura, por exemplo), assim como a de textos de cunho ético ou moral. Tais problemas, no entanto, não deverão nos preocupar, na medida em que o próprio Wittgenstein, em sua obra tardia, se encarrega de fazer a terapia da concepção de linguagem que dá sustentação ao modelo do Tractatus. ${ }^{5}$

\footnotetext{
${ }^{5}$ Não é difícil identificar a relação de afiguração entre linguagem e mundo como sendo precisamente aquele modelo que Wittgenstein (1989b) associa a uma concepção referencialista (ou agostiniana) de linguagem, no início das Investigações Filosóficas (§ 1): “[...] as palavras da linguagem denominam objetos — frases [proposições] são ligações de tais denominações. [...] cada palavra tem um significado. Esse significado é
} 
Por outro lado, é importante registrar que a cisão entre lógica e ética, tal como pode ser vista no primeiro Wittgenstein, dificulta o gesto, não de todo incomum, de tentar reintroduzir uma ideia de "essência do sentido", independente do intérprete, que se pensava superada nos Estudos da Tradução, quando agora se faz uma discussão sobre a ética nesse domínio. Isso porque, pelos motivos já expostos, o "certo vs. errado" no domínio da lógica, e das relações referenciais - ou, se quisermos, denotativas —, será necessariamente diverso do “certo vs. errado" ou do "bom vs. ruim" da ética/estética. Uma vez aceita essa premissa, fica descartada qualquer possibilidade de usar critérios referenciais, ou pretensamente objetivos (no sentido tradicional), no julgamento de questões éticas/estéticas.

\section{Obra tardia: ética na (auto)terapia conceitual}

Se acompanharmos atentamente o desenvolvimento posterior da obra de Wittgenstein, veremos que é exatamente o campo do sentido propriamente dito que se aproximará cada vez mais de um tipo de fundamentação semelhante àquele antes reservado à ética/estética - ou seja, do fundamento sem fundamento a que remete o filósofo ao sugerir que, ao final de uma cadeia de razões, quando já não posso fornecer outras, a pá entorna na rocha dura da pura convicção, e digo simplesmente "é assim que eu ajo" — fornecendo talvez até causas empíricas para agir assim (Investigações, § 217). Esse fundamento sem fundamento não deixa de ser um quadro de referência que dá sentido àquilo que fazemos nos jogos de linguagem que compõem nossas formas de vida. Assim como o sistema ético, ele tem uma dimensão absoluta, por ser padrão de medida, não podendo, portanto, ser mensurado. Mas, atenção: esse absoluto não significa eterno. Longe disso, a disponibilidade a questionar as próprias convicções, a imaginar aquilo que seria inimaginável, é um componente essencial da terapia do dogmatismo na obra tardia de Wittgenstein.

Na discussão contemporânea, há uma certa dificuldade em entender como se pode resguardar o conceito de objetividade sem um fundamento último, de natureza ontológica. Dificuldade semelhante àquela de imaginar um quadro de referência ético que seja absoluto,

agregado à palavra. É o objeto que a palavra substitui." A obra tardia do filósofo é marcada exatamente pelo esforço de fazer a terapia dessa concepção de linguagem e das confusões conceituais que ela engendra. Registrese também a grande proximidade de noções como "intracódigo semiótico", mobilizada(s) por Haroldo de Campos (1981: 181) em sua teorização sobre a tradução, com o papel que cabe ao conceito de tradução na teoria pictórica do Tractatus. Nesse sentido, se a concepção de linguagem do Tractatus é essencialista, aquela de Haroldo de Campos (e de outros expoentes do concretismo brasileiro) também o é — apesar de toda aparência em contrário. A esse respeito, vide a exemplar análise de Silene Moreno (2001), aludida também no argumento de Cristina Rodrigues (2007) sobre a não universalidade da ética em tradução, assim como minha própria discussão do tema (Oliveira, no prelo). 
mas não universal. A superação de dificuldades dessa natureza é uma das apostas feitas pela pragmática filosófica desenvolvida por Arley Moreno a partir da terapia conceitual wittgensteiniana. Dialogando com alguns expoentes da tradição filosófica, o autor sugere que

embora a realidade formal de uma ideia, no sentido de Descartes, não esteja garantida pela existência de uma realidade extralinguística, sua objetividade não estaria, por isso, necessariamente perdida (...). Pelo contrário, a objetividade das ideias poderá ser garantida pelas regras gramaticais dos jogos de linguagem em que estiver inserido o conceito que lhe corresponde. (Moreno, 2008: 258; cf. também Moreno, 2005: 405)

Na continuidade do argumento, registra-se que o mesmo modelo referencial usado por Descartes servirá a Husserl para garantir a intersubjetividade das ideias e inaugurar a atitude ética que permite admitir, paralelamente à nossa própria intersubjetividade, a "combinação de categorias que nos são estranhas - por exemplo, das crianças, dos estrangeiros, dos loucos, dos extraterrestres etc." (Moreno, 2008: 259; cf. também Moreno, 2005: 406). Retenhamos, desses dois trechos: 1) que a objetividade independe de uma fundamentação ontológica (como aquela do modelo referencial); 2) que a atitude ética, ainda dentro desse modelo referencial, admite a possibilidade de outras formas de intersubjetividade. Mas essa intersubjetividade, assim entendida (na esteira de Husserl), não afetaria os fundamentos lógicos do mundo, ao permanecer no modelo referencial.

Ainda segundo Moreno, a gramática wittgensteiniana e sua terapia conceitual levam a uma

outra atitude, igualmente ética, mas também epistêmica, que conduz à relativização interna das formas de produção do sentido; não apenas o "nosso mundo" ou a nossa intersubjetividade devem ser eticamente relativizados como também devem sê-lo epistemicamente, porque são da mesma natureza daqueles que lhe são estranhos. [...] Eis o esforço ético para a vontade gramatical, epistemicamente esclarecida pela terapia. (ib., ibid.)

Retenhamos que a ideia de relativizar evocada por Moreno significa, em relação a Husserl, a aceitação de que outros possam pensar diferente, mas sem abalar nossa certeza de que nossa forma de pensar seria a logicamente correta - como o próprio rol dos exemplos já sugere: loucos, crianças, estrangeiros, extraterrestres. Já no tocante à relativização epistêmica no bojo do combate ao dogmatismo empreendido por Wittgenstein, isso significa a disposição, em princípio, a aceitar a possibilidade da existência de outras fundamentações gramaticais, de outros quadros de referência. Tal relativização não significa, no entanto, que esses quadros de referência passem a ser "relativos", i.e., que deixem de ser, num certo 
sentido, absolutos. Reside justamente aí a distinção primordial entre os conceitos de lógica e gramática (no sentido wittgensteiniano). A lógica, além de fundamento absoluto, é compreendida como atemporal (não ocorre no tempo dos fenômenos) e imutável (vige para sempre). A gramática é um fundamento que, além de ter força igual à da lógica, é também atemporal - mas não vige para sempre, i.e. pode ser substituído por um outro fundamento, que passa então a ocupar seu lugar, novamente com igual força que a lógica. ${ }^{6}$

As distinções entre o universal e o absoluto, e entre o relativo e o regional, podem nos ajudar a aparar algumas arestas que surgem no debate contemporâneo, envolvendo as relações entre a ética e a fundamentação do sentido, notadamente no embate entre as posições pósestruturalistas e outras vertentes não-essencialistas - como a posição defendida por Paulo Henriques Britto, que nos propõe mobilizar Wittgenstein nessa discussão:

Quando defendem suas posições, os teóricos pós-estruturalistas costumam argumentar que a única alternativa a elas é uma crença platônica no significado estável, eterno e transcendente, inscrito na carne das palavras. Mas essa estratégia retórica não deve ser levada a sério. É perfeitamente possível rejeitar as desconstruções radicais das categorias básicas em que se funda a linguagem sem cair numa posição essencialista. É o que fazem os autores que seguem o caminho aberto por Wittgenstein, uma proposta que evita tanto a Cila do essencialismo quanto a Caríbdis do ceticismo radical. E o ponto de partida deve ser a crítica ao pressuposto básico da postura pós-estruturalista - a ideia de que, na ausência de absolutos, não resta nenhum valor. Ousemos discordar: restam valores relativos, o que não é a mesma coisa que nada. (2007: 11)

Pelo que expus até aqui, fica evidente que concordo com Britto em linhas gerais, mas discordo em alguns pontos nevrálgicos. É certo que há outras alternativas antiessencialistas à visada da desconstrução, sendo a concepção de linguagem do segundo Wittgenstein um excelente candidato a cumprir essa função. Por outro lado, o papel de norma que é necessário para que possamos fazer avaliação de qualidade nas traduções, como sugere Britto ao longo do trabalho citado, só pode ser exercido se tivermos um quadro de referência que tenha um certo caráter absoluto, na condição mesma de padrão de medida. Que esse padrão possa ser regional, ou necessariamente seja regional (por estar inserido nas formas de vida das diferentes culturas), não modifica seu caráter absoluto - enquanto dure, para evocar o Vinícius de nossa epígrafe. Retomando o raciocínio de Moreno, citado acima, é perfeitamente possível resguardar o conceito de objetividade, que é garantida "pelas regras gramaticais dos

\footnotetext{
${ }^{6}$ O leitor familiarizado com a obra de Thomas Kuhn (1987), já evocada na nota 4 acima, não terá maiores dificuldades em perceber a semelhança tópica entre as duas abordagens — a despeito das diferenças mais profundas entre o paradigma científico segundo Kuhn e as noções de paradigma e quadro de referência no segundo Wittgenstein.
} 
jogos de linguagem em que estiver inserido o conceito que lhe corresponde". Ora, os critérios de avaliação sugeridos por Britto cumprem exatamente esse papel de regra gramatical, e por isso mesmo podem ser uma norma com base na qual é perfeitamente possível fazer avaliações de mérito na tradução - dentro desse quadro de referência, entenda-se bem. Por estarem inseridos em um quadro de referência, tais critérios são regionais; mas, por servirem de norma ou critério de correção nesse quadro, são também absolutos. Certamente, é muito mais do que um nada; mas, por outro lado, não é algo relativo — pelo contrário: é o ponto, ou sistema, face ao qual se fazem as relações. A dificuldade reside talvez em entender como algo possa ser regional e "finito" (ou provisório: não vige para sempre), porém mesmo assim absoluto. Mas é precisamente isso o que podemos aprender com Wittgenstein.

\section{Certezas de base}

Tendo em vista as distinções propostas acima, cabe agora fazer um excurso por algumas questões concernentes ao conhecimento, começando por lembrar os riscos de incorrermos num outro tipo de mal-entendido, que envolve também a noção de relativo. Refiro-me aqui àquelas leituras que, diferentemente do que faz Britto no argumento supracitado, atribuem a Wittgenstein uma postura relativista, ou mesmo cética — sobretudo na obra tardia. Como essa visão pode ter algum impacto na recepção do filósofo na área de Estudos da Tradução, cumpre também, profilaticamente, registrá-la aqui, ainda que não possamos desenvolver o tópico em maior profundidade. Remeta-se então à discussão de Margutti Pinto (2008) com alguns representantes do chamado neopirronismo brasileiro, nomeadamente Danilo Marcondes e Plínio Smith, a qual tem o mérito de apontar para alguns dos problemas mais comuns e sugerir respostas convincentes, i.e. boas alternativas às leituras propostas pelos interlocutores do autor. No tocante à percepção de que Wittgenstein faria um questionamento "interno" das posturas filosóficas que discute (um pouco à moda da desconstrução, poderíamos acrescentar), Margutti Pinto (2008: 280, nota 8) lembra que

Wittgenstein não questiona teorias filosóficas "de dentro" delas mesmas [i.e., não explora suas aporias, como faz a desconstrução]. Na verdade, ele as questiona "de dentro" da perspectiva de uso comum das palavras e assim mostra sua inadequação. Isso certamente não deve ser definido como "um tipo de estratégia cética". (observação entre chaves acrescida por mim)

No que diz respeito à aproximação que costuma ser feita entre a metáfora da escada no Tractatus (6.54) e o ceticismo pirrônico, o autor lembra ainda que, no próprio Tractatus 
(6.51), Wittgenstein diz que "o ceticismo é um contrassenso porque levanta dúvidas onde nenhuma questão pode ser perguntada" (Margutti Pinto, 2008: 281-282, nota 9).

Tal entendimento perpassa toda a obra do filósofo austríaco e ressurge de modo revigorado em Da certeza (Wittgenstein, 2004), um de seus últimos escritos, no qual trata exatamente da inadequação da postura cética radical e discute, sob vários ângulos, a relação entre o quadro de referência (ou norma) e as proposições descritivas, nas quais algo é caracterizado como certo ou errado (bom ou mau, belo ou feio etc.), com base exatamente nesse quadro de referência. No momento em que tivermos uma compreensão mais adequada sobre a natureza das certezas de base, e sobre o modo como elas se manifestam em nossas práticas linguísticas (inclusive com alternância no uso das proposições, ora como norma ou padrão de correção, ora como aquilo que pode estar certo ou errado, i.e. descrição), teremos melhores condições de nos desfazermos de certas confusões conceituais concernentes aos fundamentos do conhecimento e do valor - os dois grandes temas em jogo no presente trabalho.

Um dos pontos a reter é que assumimos determinados fatos/valores como verdadeiros, ou válidos, sem que eles nos tenham sido, de algum modo, provados numa cadeia de razões. É isso o que está por detrás do conceito wittgensteiniano de imagem de mundo (Weltbild):

Mas não cheguei à minha imagem de mundo por convencer-me, a mim mesmo, de sua correção, nem por ter sido convencido de sua correção. Ela é antes o pano de fundo herdado sobre o qual distingo o verdadeiro do falso. (Da certeza, § 94)

Para não perdermos de vista os Estudos da Tradução e, neles, o debate essencialismo vs. relativismo, retome-se aqui ao célebre ensaio Is there a text in this class?, de Stanley Fish (2003) - cuja estruturação retórica coloca-o, em vários pontos, bem mais próximo de Wittgenstein (via Searle) do que de Derrida:

(...) ambas as interpretações deram-se precisamente em função das normas públicas e constitutivas (da linguagem e da compreensão) evocadas por Abrahams. Ocorre simplesmente que essas normas (...) são inerentes a uma estrutura institucional, na qual se ouvem tais enunciados como já organizados - com relação a determinados fins e objetivos pressupostos. (Fish, 2003: 306)

Mais adiante, lemos:

Seria de fato perturbador, se a norma fosse flutuante e indeterminada. Mas não há um tal estado: sentenças emergem apenas em situações e, no âmbito dessas situações, o sentido normativo de um enunciado será sempre óbvio ou, no mínimo, acessível; mesmo que, em 
outra situação, a mesma sentença, não mais a mesma, tenha outro sentido normativo - o qual não será tampouco menos óbvio ou acessível. (p. 308)

Note-se que o emprego do termo "normativo" feito por Fish no último exemplo (o que é dado como "certo") implica significação diversa do escopo do conceito em Wittgenstein (o que define "certo" e "errado", "pertinente" ou "não pertinente" etc.). Mas há certamente um paralelo muito claro entre os dois argumentos - sobretudo levando-se também em conta a compreensão de norma como pano de fundo (no sentido wittgensteiniano), no trecho anterior de Fish. Se tal aproximação for válida — e há bons motivos para crer nisso —, cabe rever o alinhamento automático de Stanley Fish ao campo relativista, como parecem propor, por exemplo, Ana Paula Grillo-El-Jaick (2007: 14), de modo explícito, e Paulo Henriques Britto (2007: 10), de modo implícito.

O próprio Fish, ao final de seu ensaio, arrola argumentos que mobilizam tópicos centrais na obra tardia de Wittgenstein - ainda hoje objeto de intensas controvérsias dentre os comentadores do filósofo. Fish lembra, por exemplo, que os pressupostos e opiniões de um indivíduo não são simplesmente "seus", mas refletem antes uma "compreensão compartilhada" (p. 220); ou seja, em termos wittgensteinianos, um acordo tácito que define o próprio fundamento do sentido: seu quadro de referência. Segundo o crítico literário norteamericano, esse seria o motivo pelo qual é "tão difícil para alguém cujo próprio ser é definido pela posição que ocupa em uma instituição (...) explicar para alguém fora dela uma prática ou um sentido que não lhe demanda qualquer explicação, porque a vê como natural” (p. 220221). Agrega ainda que, "se pressionada", tal pessoa tenderia a dizer algo como: "mas é simplesmente assim que isso é feito", ou ainda "mas não é óbvio"? (p. 321). Estamos aqui justamente naquele "solo duro" da convicção, onde findam as cadeias de razões, do qual falava Wittgenstein nas Investigações (§ 217): "Se esgotei as justificações, então atingi a rocha dura e minha pá entortou. Então estou inclinado a dizer: "é assim que eu ajo”".

Para os Estudos da Tradução, seria certamente proveitoso retomar o ensaio de Fish, cujo alinhamento automático a um campo tido por relativista vai muito além dos dois exemplos citados acima, para examinar em que medida seus argumentos são compatíveis com a visão de linguagem (e do sentido, da tradução, dos valores etc.) que informa a obra tardia de Wittgenstein. Como tal exame implica todo um programa de pesquisa adicional, contentemonos, por ora, com as observações arroladas acima, e registremos uma outra dificuldade que está provavelmente na origem de não poucas confusões interpretativas: a flutuação nos usos de uma mesma proposição. 
Retomemos para isso um exemplo explorado por Cristiane Gottschalk e aludido por vários outros participantes do último Colóquio Wittgenstein em Campinas (Certeza?), em setembro de 2009. Nesse exemplo, o filósofo reafirma o caráter não questionado das proposições de base e agrega um aspecto adicional de grande relevância, a saber, que uma mesma proposição pode ser usada ora como critério, ora como sintoma:

É claro que nem todas as proposições empíricas têm o mesmo estatuto, já que se pode formular uma proposição e convertê-la de proposição empírica em norma de descrição.

Pense-se na investigação química. Lavoisier faz experiências com substâncias no seu laboratório e conclui, então, que ocorre determinado fenômeno quando há combustão. Não diz que poderia ter ocorrido de outro modo, noutra ocasião. Ele mobiliza uma determinada imagem de mundo - não, evidentemente, uma que ele tivesse inventado: adquiriu-a quando criança. Digo imagem de mundo e não hipótese, porque é o fundamento indiscutível de sua pesquisa e assim também não é sequer verbalizada. (Da certeza, § 167)

Segundo Gottschalk, esse trecho deixa claro

o papel que as convicções mais profundas de Lavoisier desempenham em sua pesquisa. São elas o que [lhe] permite concluir que uma substância $\mathrm{X}$ reage sempre com uma substância $\mathrm{Y}$ da mesma maneira, dadas as mesmas circunstâncias. Esta descrição empírica é então convertida em uma norma de descrição. Ser X ou Y agora pressupõe esta reação entre estas substâncias. Passa a fazer parte da definição de cada uma delas: é critério para ser X ou Y (cf. Da certeza, § 168). (Gottschalk, 2009: 10 - no manuscrito)

Ora, se a imagem de mundo organiza até mesmo nossa relação com as chamadas ciências empíricas, ela atua também sobre o fundamento da significação em outras construções de sentido, e na atribuição de valores. Como no caso da avó de Proust descrito no ensaio de Bassnet \& Lefevere (1990), nós herdamos certos valores, expectativas e padrões de avaliação - adquirindo-os (de forma inquestionada) ao longo de nossa formação. Para que tais valores possam ser mudados, temos de passar por um processo que é antes uma conversão do que um convencimento (cf. Da certeza, § 262). Podemos, é claro, mudar nossos critérios (sejam eles sobre o conhecimento ou éticos/estéticos), ao longo de nossa vida, à medida em que formos apresentados a outras possibilidades, a outros quadros de referência. A questão torna-se problemática apenas quando tais quadros de referência, novos ou velhos, são apresentados de modo dogmático - como se eles se assentassem numa fundamentação última e inquestionável: um fundamento com fundamento (contrariamente à ideia, expressa nas Investigações, $\S 217$, de fundamento sem fundamento). Note-se bem a diferença: inquestionado é o modo como assimilamos o pano de fundo herdado da tradição, ao longo de 
nossa formação; dizer que algo é inquestionável é atribuir-lhe caráter ontológico — necessário e imutável.

Encerrando nosso excurso pela questão do conhecimento, voltemos então ao tópico da avaliação em tradução, tal como colocado por Paulo Henriques Britto, para registrar agora um outro aspecto relevante, complementar ao anterior, qual seja: o tom da discussão. Diante da forma enfática como Britto apresenta seus argumentos, surgem dúvidas sobre sua disposição a vir, eventualmente, a questionar seus próprios critérios, ou melhor, a admitir a possibilidade de outros - também como fundamento, como quadro de referência. Sem essa disponibilidade, estaríamos distantes da atitude ética do segundo Wittgenstein, atitude essa derivada da percepção de que nossos quadros de referência, em última instância, carecem de uma fundamentação mais "profunda", de natureza ontológica. Em outras palavras: no momento em que defendermos a utilização dos critérios que propomos, de nosso quadro de referência, de maneira dogmática, abandonaremos necessariamente "o esforço ético para a vontade gramatical, epistemicamente esclarecida pela terapia”, nos termos usados por Moreno (2008: 259) na citação acima.

\section{Critério e sintoma}

O dogmatismo de certas posturas é condicionado provavelmente por dois fatores. Um deles é que nem sempre é fácil distinguir de imediato o uso criterial do sintomático ou, em outras palavras, o normativo do descritivo. Se tudo for sintoma, então o quadro de referência acaba sendo percebido como fundamento último - e necessário, imutável. Em outros termos, a norma é interpretada naturalisticamente. Num certo sentido, é isso o que ocorre num caso discutido por Wittgenstein — a ideia de que nossos sentidos nos enganam. Segundo o filósofo, quando atribuímos aos sentidos a capacidade de nos "enganar", por exemplo na sensação de chuva, i.e. quando tomamos determinadas impressões faciais, sensações de frio ou calor etc., como sintomas de que choverá, estamos, na verdade, nos esquecendo de que fomos nós mesmos que definimos tais impressões físicas como critérios para entender a linguagem das sensações (Investigações, § 354-355; note-se o paralelo com a ideia de definição mobilizada em Da certeza, § 168, conforme evocado por Gottschalk na citação acima).

O segundo fator reside no caráter de profundidade que têm nossos sistemas de crenças, nossos projetos ou sistemas éticos/estéticos etc. — ou seja, nossas imagens de mundo. Por serem profundas, i.e. por terem - aparentemente — o caráter de necessidade (já que são o próprio quadro de referência), tais crenças tendem a ser naturalizadas, a serem vistas não só 
como um fundamento suficiente para nossos julgamentos (o que são, de fato), mas também como necessárias - não poderiam ser outras. É nesse contexto que surge a confusão entre o que é sintoma ou critério.

Tanto na crítica literária como nas resenhas de tradução, não é raro encontrarmos argumentos que caracterizam como sintoma ("prova") de uma tradução "mal feita" aquilo que é, na verdade, a expressão de uma interpretação ou tradução feita com base em outros critérios. Ora, se os critérios são outros, o que conta como "bem" ou "mal" feito certamente não é o mesmo. O que não significa que possamos abrir mão de diferenciarmos entre o "bem" ou "mal" feito, ou que possamos deixar de avaliar — de um modo consciente e assumido, como aquele que nos propõe Paulo Henriques Britto. De resto, convém sempre lembrar, a avaliação implícita é inevitável: vem automaticamente quando assumimos esse ou aquele ponto de vista — ou somos assumidos por eles.

Vejamos alguns exemplos de flutuação entre critério e sintoma na tradução, retomando para isso alguns conceitos de Wittgenstein que são de grande relevância para nossa própria discussão. Nas Investigações (§ 355), a versão de José Carlos Bruni traz a seguinte redação: "Não se trata do fato de que nossas impressões sensíveis possam nos enganar, mas de que compreendemos sua linguagem. (E essa linguagem repousa, como qualquer outra, numa convenção.)" O uso do termo "convenção" para verter Übereinkunft nesse trecho pode ser lido como um sintoma de que Bruni usou como critério um sentido não técnico do termo, ou um sentido técnico que se alinhe com as chamadas interpretações convencionalistas do acordo tácito invocado por Wittgenstein, nas próprias Investigações (§ 241): "Correto e falso é o que os homens dizem; e na linguagem os homens estão de acordo [... stimmen die Menschen überein]. Não é um acordo [Übereinstimmung] de opiniões, mas de formas de vida" (na redação de Bruni: “não é um acordo sobre as opiniões, mas sobre o modo de vida”).

De passagem, note-se que, exatamente por ser esse um acordo de formas de vida, trata-se de um acordo tácito (como aquele que informa as imagens de mundo). Dado que a tradução de Übereinkunft feita por Bruni no $§ 355$ não se coaduna com aquela de seu sinônimo Übereinstimmung no $§ 241$ (onde o foco está no próprio conceito), ganha força a hipótese de uma tradução sintomática de um uso não técnico do termo (ou melhor: do conceito), face àquela de uma opção técnica por uma leitura convencionalista do filósofo. ${ }^{7}$

\footnotetext{
7 Note-se que o termo Übereinkunft, para além da evidente sinonímia, traz em si a marca do aspecto "tácito" de modo ainda mais acentuado que Übereinstimmung — o que se mostra pelo rol de exemplos arrolados para o uso dos dois termos em dicionários monolíngues, e está também registrado no mapa de concordâncias obtido na base de dados da Universidade de Leipzig (cf. http://wortschatz.uni-leipzig.de).
} 
Estaria caracterizado um alinhamento à leitura convencionalista, se também no $§ 241$ fosse adotado o termo "convenção" - opção que é dificultada pelo fato de que Wittgenstein explicita não se tratar de um acordo de opiniões (o que, por sua vez, não impediu que a leitura convencionalista de alguns comentadores ganhasse um grande número de adeptos).

Já no caso da polêmica entre José Artur Giannotti e Bento Prado Jr. sobre a melhor tradução da expressão vernünftiger Mensch em Da certeza ( $\$ 575)$, o que está em jogo é certamente o critério para uma interpretação adequada da obra do filósofo austríaco. Para Giannotti, trata-se aqui de um homem racional; para Prado Jr., de um homem razoável. A depender da opção feita, Wittgenstein aproxima-se ou afasta-se da tradição em que a Razão (ainda) é escrita com letra maiúscula (como na obra de Habermas, por exemplo). Ou seja, a tradução adquire aqui peso criterial, ela estabelece uma norma (cf. Oliveira, 2007: 230-236, para uma discussão mais detalhada).

No próprio encontro de Ouro Preto, foram fornecidos vários outros exemplos em que a escolha de um termo ou outro para traduzir o texto de partida adquire caráter criterial. Desses, talvez os mais evidentes estejam na disputa sobre a melhor forma de traduzir, ou mesmo editar, o Seminário 11 de Jacques Lacan, conforme nos relata sua tradutora Dulce DuqueEstrada. Ao estabelecer como deviam ser traduzidos para o português certos termos, os editores franceses procuraram definir uma norma que orientasse a leitura dos textos também na tradução. Já os discípulos de Lacan que discordaram das escolhas da própria edição francesa, inclusive levando o caso para o âmbito judicial, propuseram uma outra norma interpretativa. Não há, no caso, um acordo tácito, nem mesmo consenso, entre os especialistas que possa, inclusive, informar a leitura dos não iniciados. Mas há, certamente, uma série de outros acordos tácitos que mobilizam — ou mesmo possibilitam — a própria existência da polêmica.

Mas, como então definir, ou mesmo mudar os critérios? Bem, aqui entram as imagens de mundo, a persuasão que nos leva a mudar de ponto de vista, o consenso a que chegam os especialistas ao fim de um longo processo de discussões (e convencimento) etc. Em termos wittgensteinianos, o dogmatismo ocorre, por exemplo, quando uma imagem de mundo (Weltbild), i.e. um fundamento suficiente e quiçá mutável, cristaliza-se como visão de mundo (Weltanschauung), i.e. um fundamento que, além de necessário (ou exclusivo), é visto também como imutável.

\section{Observações finais}


É compreensível que quem defende determinado projeto ético/estético face a outros projetos concorrentes (como é o caso dos autores citados por Cristina Rodrigues), ou quem propõe um conjunto de normas para a avaliação da qualidade de traduções (como faz Paulo Henriques Britto), atribua caráter de profundidade aos princípios e valores que defende. Daí não ser fácil adotar a autoterapia no sentido wittgensteiniano, com todas suas implicações éticas e gramaticais - tais como caracterizadas por Arley Moreno. Mas, quem disse que é fácil ter uma atitude ética? Se fosse fácil, a questão já estaria perfeitamente equacionada dentro dos próprios sistemas de valores, bastaria ligar o "piloto automático" e todos os problemas estariam resolvidos. No entanto, retomando o que foi dito acima com relação à Conferência sobre a ética: não há solução automática, embora o vislumbre de uma eventual solução seja necessário para caracterizar o próprio caso como problema (envolvendo, precisamente, um conflito de sistemas).

Resumindo o itinerário percorrido até aqui, creio poder afirmar que minha visão de uma ética da tradução informada pela obra de Wittgenstein situa-se nalgum ponto entre a crítica à busca por uma ética universal, tal como formulada por Cristina Rodrigues, e a luta contra o relativismo pós-moderno, tal como empreendida por Paulo Henriques Britto. Concordo com Cristina Rodrigues, com a ressalva de que a ausência de uma ética universal não é um problema, por si só. Concordo também com Paulo Henriques Britto, sobre a necessidade de termos um quadro de referência com base no qual possamos distinguir entre o certo e o errado, o bom e o mal etc., com a ressalva de que esse quadro tem um caráter absoluto para quem o utiliza (e nesse sentido não é relativo - e sim regional), mas que a atitude ética exige que ele seja, em princípio, passível de abandono ou modificação. Falando com Vinícius de Moraes, que seja absoluto (ou infinito) enquanto dure.

Por outro lado, a inquietação ética, que surge no título da coletânea em que ambos os trabalhos foram publicados, sugere o reconhecimento de um problema que pode perfeitamente ser entendido nos termos da ética vislumbrada por Wittgenstein, tanto na sua obra inicial (ética e estética estão fora do mundo) quando na obra tardia, em que a atitude ética resulta do combate ao dogmatismo através de uma terapia conceitual que passa também pela autoterapia de nossos próprios pensamentos e valores. Trata-se de uma atitude ética que se mostra nas nossas ações, não podendo ser fixada de uma vez por todas, em um catálogo de regras e preceitos de aplicação automática. E por esse motivo, continua a ser uma ética em primeira pessoa, que se aplica sobretudo a mim mesmo, podendo eventualmente ser usada por outros — à guisa de exemplo. 
"Faça como eu faço (e não como eu digo)" — até porque eu talvez não tenha como dizer o que tem de ser feito (no sentido de fornecer suas explicações últimas). Esse seria talvez um bom caminho a seguir quando falamos de ética — inclusive na tradução.

\section{Referências bibliográficas}

BASSNET, Susan \& LEFEVERE, André (1990) "Introduction: Proust's grandmother and the thousand and one nights. The 'cultural turn' in translation studies".

Translation, history \& culture. Londres \& Nova York: Pinter Publishers.

BABENBERGER, Michael Simon (2004) "Meister Kan Te und sein Schüler Lü". Wie Wittgenstein das Rechnen verlernte - und andere philosophische Rätsel. Freiburg: Herder Verlag.

BRITTO, Paulo Henriques (2007) “É possível avaliar traduções?”. Tradução em Revista 4.

CAMPOS, Haroldo de (1981) "Post Scriptum. Transluciferação mefistofáustica". Deus e o diabo no Fausto de Goethe. São Paulo: Perspectiva,.

EL-JAICK, Ana Paula Grillo (2007) "Ceticismo/Linguagem". Tradução em Revista 4.

FISH, Stanley (2003[1980]) "Is there a text in this class?". Is there a text in this class? The authority of interpretative communities. Cambridge: Harvard University Press.

GOTTSCHALK, Cristiane (2009) "Critérios, regras, certezas". Palestra apresentada no VI Colóquio Nacional / III Colóquio internacional Wittgenstein. Campinas, IFCH/Unicamp, em 23/09.

KANT, Immanuel (1980[1788]) Crítica da razão pura. Trad. de Valério Rohden e Hudo Baldur Moosburger. São Paulo: Abril Cultural.

(2008[1785]) Fundamentação da metafísica dos costumes. Lisboa: Edições 70. (E-book disponível em http://www.consciencia.org/kantfundamentacao.shtml; acessado em 24/10/2009)

KEINERT, Maurício (s.d.) "Conflitos da razão. Liberdade e determinismo natural”. Mente $e$ Cérebro \& Filosofia 3, 27-33.

(s.d.) "Lei moral e autonomia. O conceito de vontade em Kant". Mente e Cérebro \& Filosofia 3, 34-39.

KUHN, Thomas (1987) A estrutura das revoluções científicas. São Paulo: Perspectiva.

MARGUTTI PINTO, Paulo Roberto (2008) "Sobre a natureza da filosofia: Wittgenstein e o pirronismo”. Darlei Dall’ Agnol (org.) Wittgenstein no Brasil. São Paulo: Escuta.

MORENO, Arley Ramos (2005) Introdução a uma pragmática filosófica. Campinas: Editora da Unicamp.

(2008) "Filosofia da linguagem e terapia: em direção a uma pragmática filosófica). Darlei Dall' Agnol (org.) Wittgenstein no Brasil. São Paulo: Escuta.

MORENO, Silene (2001) Ecos e reflexos: a construção do cânone de Augusto e Haroldo de Campos a partir de suas concepções de tradução. Campinas: Unicamp. (Tese de Doutorado).

OLIVEIRA, Paulo (2007) "Wittgenstein e problemas da tradução". Arley Moreno (org.) Wittgenstein: aspectos pragmáticos. Coleção CLE, v.50, p.173-242. Campinas: Unicamp.

(no prelo) "Benjamin, Derrida e Wittgenstein: forma e percepção de aspectos na tradução". João Carlos Salles (org.) Empirismo, fenomenologia e gramática. Salvador: Quarteto.

RHEES, Rush (s.d.) "Acerca de la concepción wittgensteiniana de la ética". 
WITTGENSTEIN, Ludwig (1965 [1929]: Conferencia sobre ética (Disponível no site www.philosophia.cl / Escuela de Filosofía Universidad ARCIS; acessado em 24/10/2009: http://www.philosophia.cl/biblioteca/Wittgenstein/conferencia.pdf.)

RODRIGUES, Cristina Carneiro (2007) "A prática da tradução por teóricos tradutores". Tradução em Revista 4.

SOULEZ, Antonia (2008) Une philosophie de l'acte sans une théorie de l'action. (Minicurso no V Colóquio Nacional / II Colóquio Internacional Wittgenstein. (http://www.ifch.unicamp.br/coloquio_wittgenstein/v_coloquio/programacao.html; acessado em 15/11/2009)

WITTGENSTEIN, Ludwig (1989a) Tractatus logico-philosophicus. Werkausgabe Band 1. Suhrkamp: Frankfurt a. M. (Traduções brasileiras: 1. José Arthur Giannotti. São Paulo, Companhia Editora Nacional, 1968; 2. Luiz Henrique Lopes dos Santos. São Paulo: EDUSP, 1994.)

(1965) "A lecture on ethics". Philosophical Review 74, 3-12. (Citações no texto com base na versão em espanhol Conferencia sobre ética, s.d., disponível em www.philosophia.cl / Escuela de Filosofía Universidad ARCIS. Con "Notas de las conversaciones con Wittgenstein" de Friedrich Waismann y "Acerca de la concepción wittgensteiniana de la ética" de Rush Rhees)

(1989b) Philosophische Untersuchungen. Werkausgabe Band 1. S. Suhrkamp: Frankfurt a.M. (Citações no texto seguem, com algumas modificações, a tradução brasileira de José Carlos Bruni: Investigações Filosóficas. São Paulo: Editora Nova Cultural, 1999). (2004 [1969]) Über Gewissheit. On certainty. Londres: Blackwell. (Referência no texto sob o título Da certeza, trad. de Maria Elisa Costa. Lisboa: Edições 70, 1990). 